\title{
The Effect of Hospice Consultation on Aggressive Treatment of Lung Cancer
}

\author{
Shin Hye Yoo, MD \\ Bhumsuk Keam, MD, PhD ${ }^{1,2}$ \\ Miso Kim, MD ${ }^{1}$ \\ Tae Min Kim, MD, PhD',2 \\ Dong-Wan Kim, MD, PhD ${ }^{1,2}$ \\ Dae Seog Heo, MD, PhD',2
}

${ }^{1}$ Department of Internal Medicine, Seoul National University Hospital, Seoul, ${ }^{2}$ Cancer Research Institute, Seoul National University, Seoul, Korea

\begin{abstract}
Purpose
The aims of this study were to investigate trends of aggressive treatment of non-small cell lung cancer (NSCLC) patients at the end-of-life (EOL) during the recent 5 years and examine the relationship between hospice consultation $(\mathrm{HC})$ and aggressive care.
\end{abstract}

\section{Materials and Methods}

The medical records of 789 patients with stage IIIB-IV NSCLC at Seoul National University Hospital (SNUH) who received palliative chemotherapy and died from 2010 to 2014 were retrospectively reviewed. Indicators of aggressive treatment were evaluated, and the association of $\mathrm{HC}$ with these indicators was analyzed.

\section{Results}

During the last 5 years, the frequency of $\mathrm{HC}$ increased from $26.7 \%$ to $43.6 \%$. The time interval from last chemotherapy to death increased, and the proportion of patients who received palliative chemotherapy, visited an emergency room, were admitted to intensive care unit, during the last month of life, and died in SNUH significantly decreased over time. Referral to $\mathrm{HC}$ was significantly associated with lower intensive care unit admission rates, lower out-of-hospital death rates, and less use of the chemotherapy within 1 month prior to death. Overall survival did not differ by HC.

\section{Conclusion}

The pattern of cancer care near the EOL has become less aggressive when $\mathrm{HC}$ was provided. The positive association of $\mathrm{HC}$ with better EOL care suggests that providing $\mathrm{HC}$ at the optimal time might help to avoid futile aggressive treatment.
Correspondence: Bhumsuk Keam, MD, PhD

Department of Internal Medicine,

Seoul National University Hospital,

101 Daehak-ro, Jongno-gu, Seoul 03080, Korea

Tel: 82-2-2072-7215

Fax: 82-2-2072-7379

E-mail: bhumsuk@snu.ac.kr

Received April 8, 2017

Accepted July 10, 2017

Published Online July 14, 2017

\section{Key words}

Non-small cell lung carcinoma, Aggressiveness, Hospice care, Terminal care, Palliative care, Drug therapy

\section{Introduction}

The survival rate of cancer has improved with the development of early diagnosis and improvement of treatment modalities [1]. In particular, during the recent 5 to 10 years, molecular agents that target epidermal growth factor receptor (EGFR)- or anaplastic lymphoma kinase-driven nonsmall cell lung cancer (NSCLC) have enabled patients to survive markedly longer [2]. Despite these striking advances, lung cancer remains the leading cause of death among the all cancer patients and accounts for 180 per 100,000 deaths annually in Korea [3].

Advanced lung cancer patients usually need intubation and mechanical ventilation for respiratory failure; therefore, most of their precious remaining days at end-of-life (EOL) are spent in the intensive care unit (ICU) [4]. Moreover, as their disease progresses, they often seek care at the emergency room (ER) for pneumonia or complications of brain metastases, which is a frequent site of lung cancer metastasis 
$[5,6]$. Although evidence does not clearly support a survival benefit of chemotherapeutic agents beyond third line regimens, sequential chemotherapies are commonly administered to impede cancer progression [7]. Consequently, these practice patterns increase the use of aggressive strategies for terminal lung cancer patients and thereby decrease provision of EOL care $[8,9]$.

Although attention to hospice care among patients, families and physicians has increased in recent years [10-13] and early palliative care can lead to better quality of life in NSCLC [14], the referral to hospice care is still performed too infrequently and initiated too late $[15,16]$. To achieve adequate and timely utilization of hospice resources, hospice consultation (HC) should be the primary step towards hospice referral. However, little is known about the effect of HC on the aggressive care at the EOL $[17,18]$.

In Korea, perceptions of the quality of care near the EOL have recently increased [19]. To address these changing situations, we designed this cross-sectional study to describe the current trends of aggressive care and EOL cares received by NSCLC patients in a single institution over 5 recent years, 2010-2014, and examine the relationship between hospice consultation and aggressive care.

\section{Materials and Methods}

\section{Study design and patients}

A retrospective study was conducted of patients with stage IIIB-IV NSCLC who received palliative chemotherapy in a tertiary referral hospital (Seoul National University Hospital [SNUH]) and died from January 1, 2010 to December 31, 2014. Most patients seeking care at SNUH are referred from primary or secondary hospitals. To investigate aggressiveness of care, we included only patients who were not transferred from other hospitals and not lost to follow-up during treatment. We excluded patients who did not receive chemotherapy from the analysis. EGFR tyrosine kinase inhibitor (TKI) use, according to mutation status, was classified into three groups: "matched group" included patients who received an EGFR TKI and had the evidence of EGFR mutation, "non-matched" included those who received an EGFR TKI without evidence of EGFR mutation, and "TKI non-use" included those who did not receive an EGFR TKI. Date of death was obtained from each patient's medical record or the death registration database of the Korean National Statistical Office.

\section{The indicators of aggressive care}

We modified the indicators for aggressive care from the indicators of Earle et al.'s [20] to the following: (1) number of palliative chemotherapy regimens, (2) time interval between last dose of systemic chemotherapy and death, (3) ER visit within a month of death, (4) ICU admission within a month of death, (5) no effective do-not-resuscitate (DNR) documentation, (6) never underwent consultation for hospice care, and (7) in-hospital death. Intrathecal chemotherapy, such as methotrexate or thiotepa, was excluded from systemic chemotherapy. DNR documentation was regarded effective when this choice was documented before cardiopulmonary resuscitation (CPR), including cardiac massage or intubation, was performed. Time between HC and death was also recorded. Details about the site of death (general ward or ICU) were recorded. Deaths at home, local hospital (primary or secondary hospital), or local hospice care facility were all counted as out-of-hospital deaths, not as in-hospital deaths.

\section{Hospice palliative care and hospice consultation}

As SNUH is a tertiary hospital without an inpatient ward for hospice palliative care (HPC), cancer patients in SNUH facing terminal or advanced stage have communication about their disease status and expected outcomes for the coming days with their attending physicians. The patients and family meet the nurses specialized for HPC with more than 10 years of hospice care experience after the patient agreed to the interview. The specialized HPC nurse provides the introduction of HPC including general concept and components. They also evaluate the physical and psychosocial discomfort, family support, spiritual needs, and perception of illness and goal of care of the patients, and discuss the detailed, comprehensive HPC plan through multidisciplinary team meetings held twice a week with oncologists, HPC nurses, social workers and chaplains. Patients and family caregivers also obtain information about how to communicate and to be connected with local HPC facilities or home hospice care. Advance care planning is also the major component of HPC via HC. The HPC nurse can help patients and family caregivers to make decision making by assisting them to clarify their own belief, wishes, and goals of care and to weigh risks and benefits of all the possible options.

\section{Statistical analysis}

Descriptive data was presented as mean value and standard deviation (SD) or number with percentile. To compare trends of aggressive care over time, a trend test was performed. To examine the association of aggressive care uti- 
Table 1. Baseline demographic and clinical characteristics by the year of death

\begin{tabular}{|c|c|c|c|c|c|c|}
\hline Characteristic & $\begin{array}{c}\text { Total } \\
\text { population } \\
(n=789)\end{array}$ & $\begin{array}{c}2010 \\
(n=105, \\
13.3 \%)\end{array}$ & $\begin{array}{c}2011 \\
(n=112, \\
14.2 \%)\end{array}$ & $\begin{array}{c}2012 \\
(n=203, \\
25.7 \%)\end{array}$ & $\begin{array}{c}2013 \\
(n=213 \\
27.0 \%)\end{array}$ & $\begin{array}{c}2014 \\
(\mathrm{n}=156 \\
19.8 \%)\end{array}$ \\
\hline \multicolumn{7}{|l|}{ Age at palliative diagnosis } \\
\hline Median (range) & $62(24-88)$ & $59(25-83)$ & $61(31-84)$ & $65(29-88)$ & $63(25-87)$ & $61.5(24-87)$ \\
\hline \multicolumn{7}{|l|}{ Sex } \\
\hline Male & $483(61.2)$ & $63(60.0)$ & $71(63.4)$ & $133(65.5)$ & $127(59.6)$ & $89(57.0)$ \\
\hline Female & $306(38.8)$ & $42(40.0)$ & $41(36.6)$ & $70(34.5)$ & $86(40.4)$ & $67(43.0)$ \\
\hline \multicolumn{7}{|l|}{ Histology } \\
\hline $\mathrm{ADC}$ & $596(75.5)$ & $70(66.7)$ & $82(73.2)$ & $134(66.0)$ & $175(82.2)$ & $135(86.5)$ \\
\hline $\mathrm{SqCC}$ & $112(14.2)$ & $14(13.3)$ & $18(16.1)$ & $37(18.2)$ & $26(12.2)$ & $17(10.9)$ \\
\hline Others & $81(10.3)$ & $21(20.0)$ & $12(10.7)$ & $32(15.8)$ & $12(5.6)$ & $4(2.6)$ \\
\hline \multicolumn{7}{|l|}{ Smoking history } \\
\hline Never-smoker & $370(47.1)$ & $55(53.9)$ & $56(50.0)$ & $78(38.4)$ & $109(51.2)$ & $72(46.2)$ \\
\hline Current or ex-smoker & $416(52.9)$ & $47(46.1)$ & $56(50.0)$ & $125(61.6)$ & $104(48.8)$ & $84(53.8)$ \\
\hline \multicolumn{7}{|l|}{ Palliative reason } \\
\hline Initial & $721(91.4)$ & $93(88.6)$ & $100(89.3)$ & $189(93.1)$ & $198(93.0)$ & $141(90.4)$ \\
\hline Recurred & $68(8.6)$ & $12(11.4)$ & $12(10.7)$ & $14(6.9)$ & $15(7.0)$ & $15(9.6)$ \\
\hline \multicolumn{7}{|l|}{ Site of metastasis } \\
\hline Brain & $213(27.0)$ & $21(20.0)$ & $30(26.8)$ & $50(24.6)$ & $65(30.5)$ & $47(30.1)$ \\
\hline Lung & $292(37.0)$ & $60(57.1)$ & $42(37.5)$ & 75 (36.9) & $58(27.2)$ & $57(36.5)$ \\
\hline Liver & $122(15.5)$ & $13(12.4)$ & $26(23.2)$ & 27 (13.3) & 30 (14.1) & $26(16.7)$ \\
\hline Bone & 307 (38.9) & $35(33.3)$ & $37(33.0)$ & $83(40.9)$ & $83(39.0)$ & $69(44.2)$ \\
\hline $\mathrm{LN}$ & $196(24.8)$ & $28(26.7)$ & 35 (31.3) & $43(21.2)$ & $51(23.9)$ & $39(25.0)$ \\
\hline Pleura & $211(26.7)$ & $30(28.6)$ & $28(25.0)$ & 45 (22.2) & $57(26.8)$ & $51(32.7)$ \\
\hline Other $^{\text {a) }}$ & $126(16.0)$ & $20(19.0)$ & $22(19.6)$ & 37 (18.2) & $27(12.7)$ & $20(12.8)$ \\
\hline
\end{tabular}

Values are presented as number (\%) unless otherwise indicated. ADC, adenocarcinoma; SqCC, squamous cell carcinoma; LN, lymph node. ${ }^{\text {a)}}$ Other location of metastasis included pericardium, chest wall, adrenal gland, kidney, peritoneum, bowel, and soft tissue.

lization with HC, we performed Student $t$ test for continuous variables and chi-square test for categorical variables. Overall survival (OS) was defined as time from the date of palliative diagnosis (stage IIIB or IV) to the date of death using Kaplan-Meier estimation. The log-rank test was performed to compare OS according to HC. Statistical significance was defined as two-sided $p<0.05$. All statistical tests were twosided and were performed using STATA ver. 12 software (StataCorp LP, College Station, TX).

\section{Ethical statement}

The Institutional Review Board (IRB) of Seoul National University Hospital approved the study protocol (IRB number: 1703-154-840). All studies were conducted according to the guidelines of the Declaration of Helsinki for biomedical research. The informed consent was waived.

\section{Results}

\section{Patient demographics and clinical characteristics by year of death}

The electronic medical records of 894 patients with stage IIIB-IV NSCLC who were treated with palliative chemotherapy and died from 2010 to 2014 were reviewed. Among these 894 patients, only those 789 patients who maintained SNUH follow-up visits near their death were included in the analysis. Table 1 shows their demographics and clinical characteristics at the time of diagnosis according to the year of death. Median age was 62 years, ranging from 24 to 88 years. In all 5 years, the majority of patients was male (from $57 \%$ to $65.5 \%$ ) and had the histologic type adenocarcinoma (from $66.0 \%$ to $86.5 \%$ ). In 2012 and 2014, more than half of total patients were current or ex-smokers. 


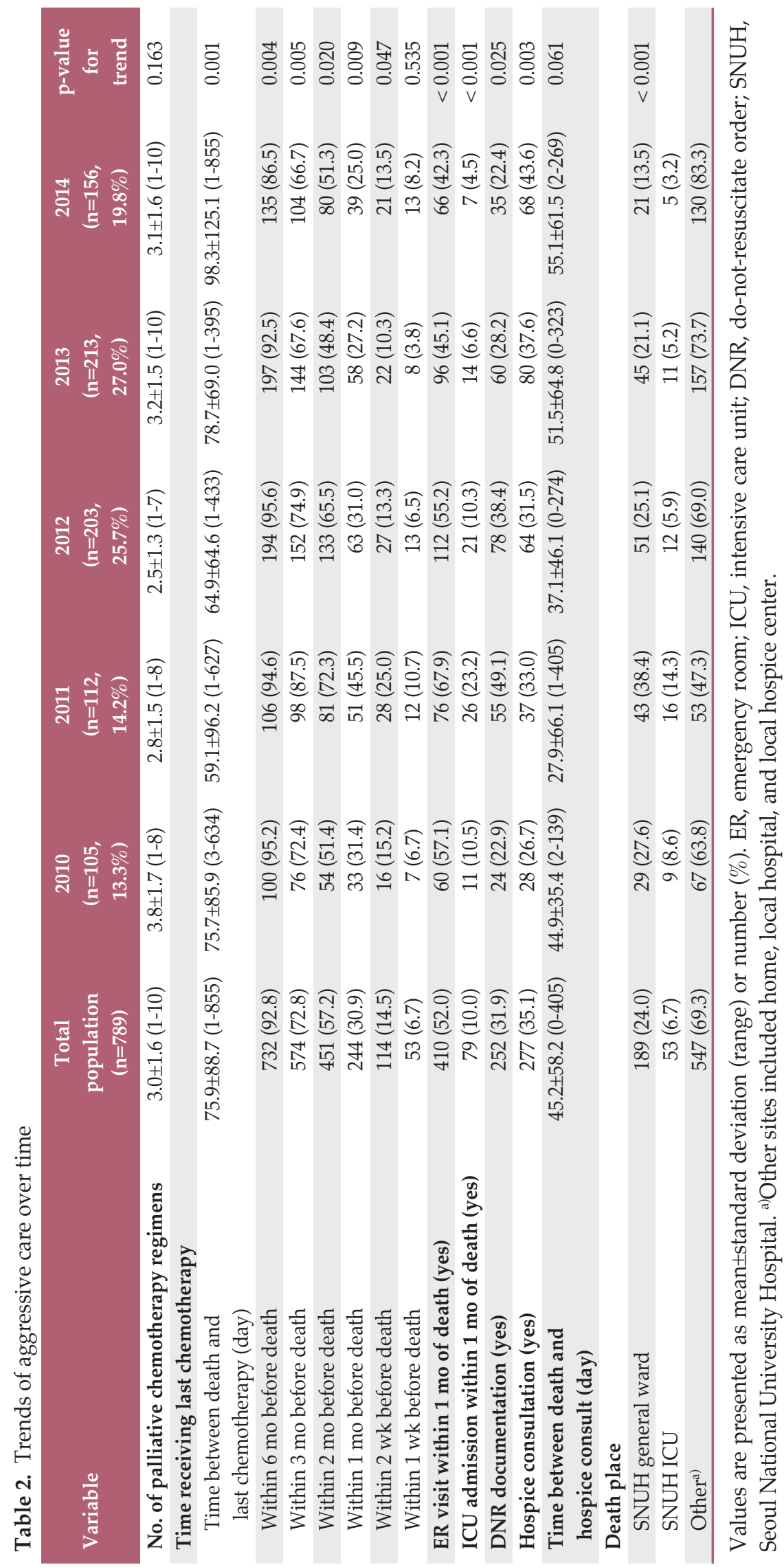


Table 3. Association of hospice consultation with aggressive care

\begin{tabular}{|c|c|c|c|}
\hline \multirow{2}{*}{ Variable } & \multicolumn{2}{|c|}{ Hospice consultation } & \multirow{2}{*}{ p-value } \\
\hline & Yes $(n=277)$ & No $(n=512)$ & \\
\hline No. of palliative chemotherapy regimens & $3.4 \pm 1.5$ & $2.8 \pm 1.5$ & $<0.001$ \\
\hline Time between death and last chemotherapy & $73.3 \pm 66.4$ & $77.2 \pm 98.8$ & 0.550 \\
\hline ER visit within a month before death & $149(53.8)$ & $261(51.0)$ & 0.450 \\
\hline ICU admission within a month before death & $10(3.6)$ & $69(13.5)$ & $<0.001$ \\
\hline DNR documentation & $81(29.2)$ & $171(33.4)$ & 0.232 \\
\hline Out-of-hospital death & $212(76.5)$ & $335(65.4)$ & 0.001 \\
\hline Chemotherapy within 6 mo before death & $259(93.5)$ & $473(92.4)$ & 0.562 \\
\hline Chemotherapy within 3 mo before death & $205(74.0)$ & $369(72.1)$ & 0.560 \\
\hline Chemotherapy within 2 mo before death & $147(53.1)$ & $304(59.4)$ & 0.088 \\
\hline Chemotherapy within 1 mo before death & $69(24.9)$ & $175(34.2)$ & 0.007 \\
\hline Chemotherapy within 2 wk before death & $24(8.7)$ & $90(17.6)$ & 0.001 \\
\hline Chemotherapy within 1 wk before death & $8(2.9)$ & $45(8.8)$ & 0.002 \\
\hline
\end{tabular}

Values are presented as mean \pm standard deviation or number (\%). ER, emergency room; ICU, intensive care unit; DNR, do-not-resuscitate order.

\section{Trends of aggressive care over time}

The mean number of palliative chemotherapy regimens was $3.0 \pm 1.6(\mathrm{SD})$. The mean time interval between death and last chemotherapy was $75.9 \pm 88.7$ (SD) days (range, 1 to 855 days) (Table 2). More than $90 \%$ of patients received chemotherapy within 6 months of death, and treatment was maintained until 1 month before death in one-third of patients. Among 789 patients, $52.0 \%(n=410)$ visited an ER within a month of death, and the mean number of ER visits was $0.7 \pm 0.7(\mathrm{SD})$. Ten percent of patients $(\mathrm{n}=79)$ were admitted to ICU within a month of death.

Regarding EOL care, $31.9 \%(\mathrm{n}=252)$ of patients signed a DNR form. Approximately one-third of 789 patients $(n=277)$ underwent more than one face-to-face consultation for HPC with the nurse practitioner by the referral from their physicians. The mean time interval between death and $\mathrm{HC}$ was 45.2 \pm 58.2 (SD) days.

We regarded out-of-hospital death as deaths that did not occur in SNUH. The proportion of patients who died in a SNUH general ward was $24 \%(\mathrm{n}=189)$, whereas $69.3 \%$ of them $(n=547)$ died out-of-hospital. The remaining $6.7 \%$ of patients $(n=53)$ died in the SNUH ICU.

Except for the year 2010, the time interval between last dose of chemotherapy and death increased over time (from 59.1 to 98.1 days). The proportion of patients who visited an ER or were admitted to the ICU during the last month of life tended to decrease over time (from $67.9 \%$ to $42.3 \%$ and from $10.5 \%$ to $4.5 \%$, respectively). Similarly, DNR documentation rate and out-of-hospital death rate increased over time (from $49.1 \%$ to $22.4 \%$ and from $47.3 \%$ to $83.3 \%$, respectively). Dur- ing all the years evaluated, upward trend was observed for the proportion of patients provided HC (from 26.7\% to $43.6 \%$ ). Tests for trend indicted significant change over time in the time interval between last chemotherapy and death $(p=0.001)$, the presence and the number of ER visits $(p<0.001$ for both indicators), the number of ICU admissions ( $<<0.001)$, DNR documentation rate $(\mathrm{p}=0.025), \mathrm{HC}$ rate $(\mathrm{p}=0.003)$, and out-of-hospital death rate $(\mathrm{p}<0.001)$.

\section{The association of hospice consultation with aggressive care}

Hospice consultation was associated with the number of palliative chemotherapy regimens (3.4 in the HC group vs. 2.8 in the no consultation group, $\mathrm{p}<0.001)$, the rates of ICU admission within a month of death $(3.6 \%$ in the HC group vs. $13.5 \%$ in the no consultation group, $\mathrm{p}<0.001$ ), and the out-of-hospital death rates (76\% in the HC group vs. $65.4 \%$ in the no consultation group, $\mathrm{p}=0.001$ ) (Table 3 ). The time interval between the last chemotherapy dose and death did not differ between these two groups. However, when this time interval was categorized into 1 week, 2 weeks, and 1 month, the proportion of patients receiving chemotherapy in the last period of death in the HC group was significantly lower than that in the no consultation group. Neither the rates of ER visits nor DNR documentation were associated with HC ( $p=0.450$ and $p=0.232$, respectively). The OS of patients who did and did not receive HC did not differ (median OS, 14.8 months [95\% confidence interval, 13.0 to $15.9]$ vs. 13.4 [95\% confidence interval, 12.0 to 14.8 ], respectively; $\mathrm{p}=0.651$ ) (Fig. 1). 


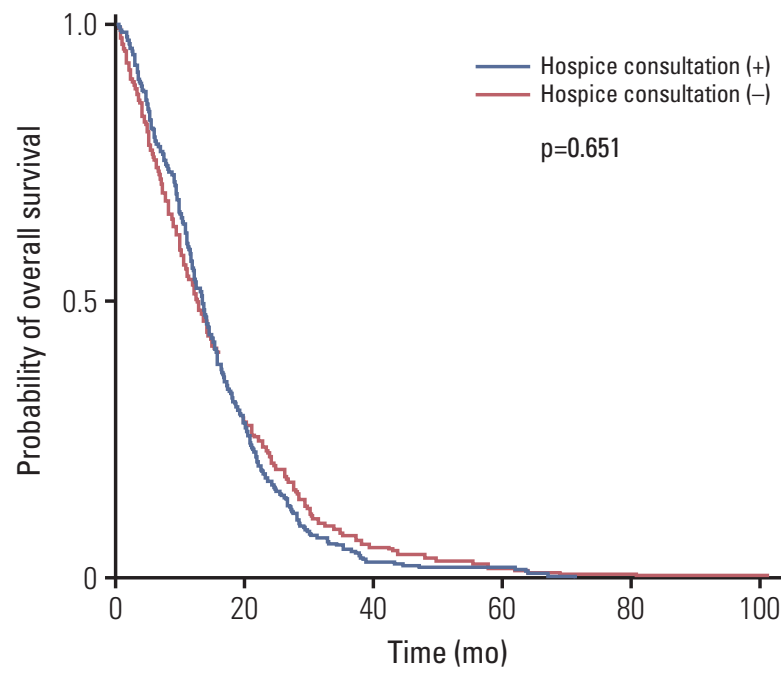

Fig. 1. Overall survival by hospice consultation in 789 patients with non-small cell lung cancer.

\section{The association of EGFR TKI use matched for mutation status with aggressive care}

Among 789 patients, $251(31.8 \%)$ received EGFR TKI with known EGFR activating mutation, 211 (26.7\%) without EGFR mutation, and 326 (41.5\%) did not receive an EGFR TKI. Most indicators of aggressive care did not differ between these three groups, except for numbers of palliative chemotherapy regimens and HC (Table 4). The number of chemotherapy regimens varied by group: non-matched group, highest; matched group, second highest; and TKI non-use group, lowest $(\mathrm{p}<0.001)$. The TKI non-use group received HC sig- nificantly less often $(29.4 \%)$ and had with the shortest mean time interval between $\mathrm{HC}$ and death (35.0 days) than the other two groups ( $\mathrm{p}=0.020$ and $\mathrm{p}=0.018$, respectively).

\section{Discussion}

Our study described the current trends of aggressive care and EOL care of patients with advanced NSCLC in the most recent 5 years. We found that the patterns of cancer care near the EOL have become less aggressive and use of $\mathrm{HC}$ has become more frequent. Patients who were referred to $\mathrm{HC}$ were likely to stop the last chemotherapy earlier, to visit ERs less often, be admitted to ICUs less often, and to die outside our referral hospital more often. Furthermore, HC was not associated with shortened OS.

The proportion of NSCLC patients receiving HC increased from $26.7 \%$ in 2010 to $43.6 \%$ in 2014 . The latter is higher than those reported in the same institution in 2002 (9.1\%) [21] and in $2012(37.6 \%)$ [12]. In addition, in our study, HC was initiated earlier than reported in previous studies [12,21] and showed an increasing trend over these 5 years. These findings might be attributed to temporal changes in acceptance of death and EOL care [11] and increased support for hospice care services.

The reduction in the proportion of patients hospitalized in ICUs may be related to increase in the frequency of $\mathrm{HC}$. The admission of terminal cancer patients to an ICU often results from impending CPR or post-CPR events due to disease progression rather than from reversible or preventable causes [22]. This futile aggressive ICU care of terminal cancer patients, including mechanical support and frequent labora-

Table 4. Association of use of EGFR TKI matched to mutation status with aggressive care

\begin{tabular}{|c|c|c|c|c|}
\hline \multirow{2}{*}{ Variable } & \multicolumn{3}{|c|}{ EGFR TKI use matched for mutation status } & \multirow{2}{*}{ p-value } \\
\hline & Matched use & Non-matched use & TKI non-use & \\
\hline No. of palliative chemotherapy regimens & $3.0 \pm 1.6$ & $3.8 \pm 1.5$ & $2.4 \pm 1.3$ & $<0.001$ \\
\hline Time between death and last chemotherapy & $72.8 \pm 77.2$ & $74.1 \pm 84.1$ & $79.2 \pm 98.7$ & 0.287 \\
\hline ER visit within a month before death & $98(46.4)$ & $130(51.6)$ & $182(55.8)$ & 0.103 \\
\hline ICU admission within a month before death & $21(8.3)$ & $16(7.6)$ & $42(12.9)$ & 0.076 \\
\hline DNR documentation & $60(28.4)$ & $80(31.7)$ & $112(34.4)$ & 0.355 \\
\hline Hospice consultation & $81(38.9)$ & $100(39.7)$ & $96(29.4)$ & 0.02 \\
\hline Time between hospice consultation and death & $61.0 \pm 81.9$ & $52.8 \pm 62.4$ & $35.0 \pm 42.9$ & 0.018 \\
\hline Out-of-hospital death & $159(29.1)$ & $167(30.5)$ & $221(40.4)$ & 0.079 \\
\hline
\end{tabular}

Values are presented as mean \pm standard deviation or number $(\%)$. EGFR, epidermal growth factor receptor; TKI, tyrosine kinase inhibitor; ER, emergency room; ICU, intensive care unit; DNR, do-not-resuscitate order. 
tory tests, improves neither survival outcome nor quality of life $[23,24]$. HC focuses mostly on advance care planning, elicits the values and preferences about aggressive care, such as CPR or mechanical ventilation, of patients and family, and helps them to make clear decisions about futile aggressive care [17]. When the patients do not receive HC, they have a little opportunity to understand the consequences of futile aggressive treatment.

Regarding the place of death, in-hospital death in a tertiary hospital, which is not considered an appropriate, ideal place of death, decreased markedly over time. This observation may also be related to a parallel increase in HC. SNUH, as a tertiary hospital, has a majority of patients who are referred in for chemotherapy, and out to local hospital or HPC facility in terminal cancer setting with limited role of chemotherapy. During HC, patients receive information about current status and prognosis, but also how to spend their remaining life meaningfully with their loved ones in comfortable and familiar places. Because patients in SNUH are often from different locations in the country, transfer to a local hospital near home might be beneficial for patients, families, and hospitals in terms of local resource utilization and better quality of EOL.

There is still a drawback in our descriptive study that it is hard to show no direct cause-and-effect relationship between $\mathrm{HC}$ and aggressive EOL care, and there may be a third factor affecting EOL care in addition to $\mathrm{HC}$, such as increased awareness and positive change of attitudes of physicians toward HPC and EOL care. Unfortunately, because of the retrospective study design, we could not evaluate whether the physicians differently perceived the essence of HPC and good EOL care over time in this study. However, in a Korean survey of attitudes toward HPC in 128 doctors caring cancer patients performed in 2010 [13], they completely answered that they were aware of the necessity of HPC for terminal cancer patients, and $47.7 \%$ of them noted that the most common barrier to hospice referral was "refusal of patient or family." This finding suggests that actual utilization of EOL care is influenced significantly by attitudes of patients or family $[25,26]$, which might be changed by HC.

Although other indicators, including ICU admission, changed in a positive direction, the DNR documentation rate decreased unexpectedly over time and was not related to HC. This can be explained to be the fact that a DNR authorization was signed by only $10 \%$ of patients who died in a different location than a general ward or ICU of the tertiary hospital SNUH. In Korea, DNR documentation is usually obtained only when death is very imminent. In previous studies of DNR documentation by Korean cancer patients $[27,28]$, the median time interval from DNR consent to death ranges from 1.76 to 6 days, which was shorter than that reported in the United States [29]. This short time does not permit enough opportunity to elicit personal value and goals, to contemplate options, and to clarify preferences for treatment. Moreover, there is no guideline for standardized DNR documentation format and appropriate timing in Korea. Currently, a standardized DNR format is not shared between hospitals; hence, further systematic support is needed.

The rate of ER visits decreased over time, but a statistical relationship with HC was not observed. The improvements in the prevention and management of chemotherapy-related side effects and wider use of oral or sublingual analgesics may have contributed to the reduction in ER visits. However, unlike ICU admission, it is difficult to avoid ER visits due to acute problems, such as respiratory distress or altered mental status [5], even if the patient is aware of their terminal status and prognosis. Regardless of HC, patients might overburden the ER of the tertiary hospital due to lack of regional medical facilities for these acute causes. Further solutions, such as home hospice care, should be considered.

Unlike previous studies in Korea [5,12,21,30], our study showed a significant temporal decrease in the use of chemotherapy within $6,3,2$, and 1 month of death, although the number of chemotherapy regimens remained unchanged. In addition, patients receiving $\mathrm{HC}$ underwent less chemotherapy within 1 month, 2 weeks, 1 week of death than those who did not receive HC. Developing anticancer therapies, cultural differences from Western countries and lower costs of cancer treatment [31] have been suggested as reasons for more aggressive cancer treatment in Korea [12,21,30]. However, our findings suggest that $\mathrm{HC}$ can provide patients and family opportunities to balance the risks and benefits, thereby avoiding futile chemotherapy, and give doctors a clearer picture of patient wishes. However, our observation that patients who received HC underwent more chemotherapy regimens is somewhat difficult to interpret. Previously, hospice care was widely believed to lead to giving up treatment [16]. The advent of new chemotherapeutic agents has increased the options for anti-cancer therapy, which tends to delay hospice care until patients and physicians attempt some form of chemotherapy [16].

We also examined whether the use of molecular targeted agents, which have fewer adverse reactions than cytotoxic chemotherapy, was associated with more aggressive endof-life care. Our results indicate that use of targeted agents does not appear to lead to more aggressive the treatments during the late stages. This differs from the findings of a previous study of diverse cancer patients that reported that targeted agents utilized in patients who received more than two regimens of chemotherapy were related to a shorter time from stopping chemotherapy to death [12]. Unlike previous studies that expected that oral chemotherapeutic might be continued until the death [30], we found that EOL care is rel- 
atively stable in patients taking targeted such agents.

The present study has unique strengths and suggests the following clinical implications. First, these favorable trends of aggressive cancer care may be explained in part by the efforts to expand HPC [13]. In addition, our findings imply that $\mathrm{HC}$ may help improve the outcomes of EOL care if it is delivered at an appropriate time. Currently in Korea, to date, the legal indications for HPC include only patients in their terminal disease status. For this reason, most of HCs are performed at the terminal or pre-terminal status. As the emerging concepts of early palliative care are adopted by clinical practice [14,32], HC could play a role as a bridge between early palliative care and HPC at the EOL in pre-terminal cancer patients. To reduce the frequency of ER visits and improve DNR documentation rates, further hospice practices that go beyond mere consultation is required.

Our study has several limitations. First, this study is retrospective. Second, although we suggest some hypothetical explanations, this observational study cannot prove a causal sequence between $\mathrm{HC}$ and associated outcomes. Factors which may affect the actual utilization of aggressive EOL care varies from not only attitudes of patients and family for EOL care [25,26], but also to changes of perception of the physicians [33], clinical practice pattern including selection of anti-cancer therapy [12], or the accessibility of EOL care resource [34]. However, in this study, we did not develop predictive model including all relevant factors. Further welldesigned prospective study including multiple factors mentioned above is needed to explain the determinants of the quality of EOL care in NSCLC. Third, because we examined only Korean NSCLC patients followed in a single institution, generalizability may be limited. The trends of aggressive care for other malignancies should be investigated in a multi-center study.

We described the current trends of less aggressive care in NSCLC patients for 5 recent years, including the use of molecular targeted agents, and demonstrated meaningful and positive associations of $\mathrm{HC}$ with better EOL care. To prevent avoidable and futile aggressive care at the EOL, HC at the optimal time should be provided to advanced NSCLC patients.

\section{Conflicts of Interest}

Conflict of interest relevant to this article was not reported.

\section{References}

1. Miller KD, Siegel RL, Lin CC, Mariotto AB, Kramer JL, Rowland $\mathrm{JH}$, et al. Cancer treatment and survivorship statistics, 2016. CA Cancer J Clin. 2016;66:271-89.

2. Forde PM, Ettinger DS. Targeted therapy for non-small-cell lung cancer: past, present and future. Expert Rev Anticancer Ther. 2013;13:745-58.

3. Oh CM, Won YJ, Jung KW, Kong HJ, Cho H, Lee JK, et al. Cancer statistics in Korea: incidence, mortality, survival, and prevalence in 2013. Cancer Res Treat. 2016;48:436-50.

4. Zarogoulidis P, Pataka A, Terzi E, Hohenforst-Schmidt W, Machairiotis N, Huang $\mathrm{H}$, et al. Intensive care unit and lung cancer: when should we intubate? J Thorac Dis. 2013;5 Suppl 4: S407-12.

5. Barbera L, Taylor C, Dudgeon D. Why do patients with cancer visit the emergency department near the end of life? CMAJ. 2010;182:563-8.

6. Kotajima F, Kobayashi K, Sakaguchi H, Nemoto M. Lung cancer patients frequently visit the emergency room for cancerrelated and -unrelated issues. Mol Clin Oncol. 2014;2:322-6.

7. Massarelli E, Andre F, Liu DD, Lee JJ, Wolf M, Fandi A, et al. A retrospective analysis of the outcome of patients who have received two prior chemotherapy regimens including platinum and docetaxel for recurrent non-small-cell lung cancer. Lung Cancer. 2003;39:55-61.
8. Sharma G, Freeman J, Zhang D, Goodwin JS. Trends in endof-life ICU use among older adults with advanced lung cancer. Chest. 2008;133:72-8.

9. Ho TH, Barbera L, Saskin R, Lu H, Neville BA, Earle CC. Trends in the aggressiveness of end-of-life cancer care in the universal health care system of Ontario, Canada. J Clin Oncol. 2011;29:1587-91.

10. Kumar P, Wright AA, Hatfield LA, Temel JS, Keating NL. Family perspectives on hospice care experiences of patients with cancer. J Clin Oncol. 2017;35:432-9.

11. Cherny NI, Catane R, European Society of Medical Oncology Taskforce on Palliative and Supportive Care. Attitudes of medical oncologists toward palliative care for patients with advanced and incurable cancer: report on a survery by the European Society of Medical Oncology Taskforce on Palliative and Supportive Care. Cancer. 2003;98:2502-10.

12. Choi Y, Keam B, Kim TM, Lee SH, Kim DW, Heo DS. Cancer treatment near the end-of-life becomes more aggressive: changes in trend during 10 years at a single institute. Cancer Res Treat. 2015;47:555-63.

13. Lee JR, Lee JK, Hwang S, Kim JE, Chung JI, Kim SY. Doctor's perception and referral barriers toward palliative care for advanced cancer patients. Korean J Hosp Palliat Care. 2012;15: 10-7. 
14. Temel JS, Greer JA, Muzikansky A, Gallagher ER, Admane S, Jackson VA, et al. Early palliative care for patients with metastatic non-small-cell lung cancer. N Engl J Med. 2010;363: 733-42.

15. Hui D, Kim SH, Roquemore J, Dev R, Chisholm G, Bruera E. Impact of timing and setting of palliative care referral on quality of end-of-life care in cancer patients. Cancer. 2014;120: 1743-9.

16. Ford DW, Nietert PJ, Zapka J, Zoller JS, Silvestri GA. Barriers to hospice enrollment among lung cancer patients: a survey of family members and physicians. Palliat Support Care. 2008;6: 357-62.

17. Lu CY, Shen WC, Kao CY, Wang HM, Tang SC, Chin TL, et al. Impact of palliative care consultation service on terminally ill cancer patients: a 9-year observational cohort study in Taiwan. Medicine (Baltimore). 2016;95:e2981.

18. Wu LF, Chu CM, Chen YG, Ho CL, Pan HH. Relationship between palliative care consultation service and end-of-life outcomes. Support Care Cancer. 2016;24:53-60.

19. Lee JE, Goo AJ, Cho BL. The current status of end-of-life care in Korea and legislation of well-dying act. J Korean Geriatr Soc. 2016;20:65-70.

20. Earle CC, Neville BA, Landrum MB, Ayanian JZ, Block SD, Weeks JC. Trends in the aggressiveness of cancer care near the end of life. J Clin Oncol. 2004;22:315-21.

21. Keam B, Oh DY, Lee SH, Kim DW, Kim MR, Im SA, et al. Aggressiveness of cancer-care near the end-of-life in Korea. Jpn J Clin Oncol. 2008;38:381-6.

22. Nasir SS, Muthiah M, Ryder K, Clark K, Niell H, Weir A. ICU deaths in patients with advanced cancer. Am J Hosp Palliat Care. 2017;34:173-9.

23. Brooks GA, Li L, Sharma DB, Weeks JC, Hassett MJ, Yabroff $\mathrm{KR}$, et al. Regional variation in spending and survival for older adults with advanced cancer. J Natl Cancer Inst. 2013;105: 634-42.

24. Wright AA, Keating NL, Balboni TA, Matulonis UA, Block SD, Prigerson HG. Place of death: correlations with quality of life of patients with cancer and predictors of bereaved caregivers' mental health. J Clin Oncol. 2010;28:4457-64.
25. Yun YH, Lee MK, Chang YJ, You CH, Kim S, Choi JS, et al. The life-sustaining treatments among cancer patients at end of life and the caregiver's experience and perspectives. Support Care Cancer. 2010;18:189-96.

26. An AR, Lee JK, Yun YH, Heo DS. Terminal cancer patients' and their primary caregivers' attitudes toward hospice/palliative care and their effects on actual utilization: a prospective cohort study. Palliat Med. 2014;28:976-85.

27. Baek SK, Chang HJ, Byun JM, Han JJ, Heo DS. The association between end-of-life care and the time interval between provision of a do-not-resuscitate consent and death in cancer patients in Korea. Cancer Res Treat. 2017;49:502-8.

28. Kim DY, Lee KE, Nam EM, Lee HR, Lee KW, Kim JH, et al. Do-not-resuscitate orders for terminal patients with cancer in teaching hospitals of Korea. J Palliat Med. 2007;10:1153-8.

29. Alsirafy SA, Mohammed AA, Al-Zahrani AS, Raheem AA, El-Kashif AT. The relation between the timing of palliative care and the frequency and timing of do-not-resuscitate orders among cancer deaths in a tertiary care hospital. Am J Hosp Palliat Care. 2015;32:544-8.

30. Lee HS, Chun KH, Moon D, Yeon HK, Lee S, Lee S. Trends in receiving chemotherapy for advanced cancer patients at the end of life. BMC Palliat Care. 2015;14:4.

31. Hwang I, Shin DW, Kang KH, Yang HK, Kim SY, Park JH. Medical costs and healthcare utilization among cancer decedents in the last year of life in 2009. Cancer Res Treat. 2016;48: 365-75.

32. Ferrell BR, Temel JS, Temin S, Alesi ER, Balboni TA, Basch EM, et al. Integration of palliative care into standard oncology care: American Society of Clinical Oncology clinical practice guideline update. J Clin Oncol. 2017;35:96-112.

33. Keating NL, Landrum MB, Rogers SO Jr, Baum SK, Virnig BA, Huskamp HA, et al. Physician factors associated with discussions about end-of-life care. Cancer. 2010;116:998-1006.

34. Tang ST, Huang EW, Liu TW, Wang HM, Chen JS. A population-based study on the determinants of hospice utilization in the last year of life for Taiwanese cancer decedents, 2001-2006. Psychooncology. 2010;19:1213-20. 